\title{
Táticas caminhantes: cinema marginal e flanâncias juvenis pela cidade ${ }^{1}$
}

Edwar de Alencar Castelo Branco UFPI

\section{RESUMO}

Este trabalho baseia-se na análise de filmes em formato não-comercial e reflete sobre as tensões existentes entre a cidade visível, configurada no discurso urbanista, e as cidades subjetivas, expressas nas práticas cotidianas de seus consumidores. O centro do argumento consiste na idéia de que os filmes em estudo configuram uma guerrilha semântica que objetivou efetuar novas leituras do espaço urbano com base na localização e ocupação dos lugares da cidade por meio de movimentos táticos. O corpo de fontes é composto por seis filmes do "espectro Torquato Neto" rodados entre 1972 e 1974 em Teresina (PI) e no Rio de Janeiro.

Palavras-chave: História; Cinema; Cidade.

\begin{abstract}
This work, from the analysis of film in not-commercial format, reflects about the existing tensions between the visible city, configured in the talk town planner, and the express, subjective cities in the routine practices of his consumers. The center of the argument consists of the idea of that the film in study configure a semantic guerrilla that planned to perform news readings of the urban space from the location and occupation of the places of the city by means of tactical movements. The body of springs is composed for six film of the "spectrum Torquato Neto" rolled between 1972 and 1974 in the cities of Teresina (PI) and Rio de Janeiro.

Keywords: History; Movies; City.
\end{abstract}

A cidade, na sua proliferação de objetos, signos e vestígios, remete a um passado com todos os futuros que ele soterrou.

Peter Pal Pelbart

Pensar a relação entre cidade e subjetividade não constitui tarefa fácil. Em parte porque nos acostumamos, ao longo do tempo, com a idéia de que o paradigma que assegura o pensamento - o qual, por sua vez, asseguraria também que nós existimos - é a fundação da cidade segundo uma razão uni- 
versal e solitária, negativa do acaso, do tempo e da história. Essa cidade como imagem do pensamento, herdada de Descartes, nos conforta exatamente porque, ao mesmo tempo em que expressa o sujeito da cidade, o eu do cogito, assegura a vitória da razão. ${ }^{2}$

Ao propor um estudo sobre a cidade como expressão do desejo, ${ }^{3}$ transcendendo-a, portanto, como imagem do pensamento, estamos nos apropriando de filmes em formato não-comercial para fixar na linguagem uma das dimensões acontecimentais da história, ao mesmo tempo em que optamos por uma noção de cidade segundo a qual o espaço urbano não se oferece facilmente à leitura. Supomos a leitura histórica das cidades, feita com base na apropriação de filmes rodados em super-8 (bitolas super oito milímetros), como algo que exige um cuidadoso trabalho de escavação sobre escombros, buscando os significados lá onde eles se escondem. E comumente se escondem entremeados em sonhos e disfarçados em imagens, pois "se o homem habita uma cidade real, ele é, ao mesmo tempo, habitado por uma cidade de sonho" (Pelbart, 2000, p.43).

Anote-se, inicialmente e como modo de situar o conjunto das fontes em estudo, que as manifestações da arte brasileira, notadamente aquelas eclodidas a partir de 1964, configuram um importante instrumento para se conhecer a realidade brasileira após a instauração do período de domínio político dos militares. Nesse período, marcado por intensa captura social e renitente fuga identitária, ${ }^{4}$ o campo artístico experimentaria profundas rupturas, em diferentes frentes, gerando uma taxonomia que traria para o cenário público categorias como Poesia Concreta, Cinema Novo, Poema Processo, Tropicália e Poesia Marginal, entre outras. Essa reconfiguração, por sua vez, tendia historicamente a um reposicionamento do papel social da arte e dos artistas, chegando mesmo a forçar a constituição de um novo acordo tácito entre consumidores e produtores das obras de arte. O fragmento a seguir, um dos testemunhos da cartografia que permitiria repensar o começo — bastante diferente da origem ${ }^{5}$ - da Tropicália, exemplifica bem esse novo quadro histórico. Para os jovens envolvidos com a arte experimental no período em estudo era preciso, antes de tudo,

Achar um novo acordo tácito a) Por meio de um choque de presentidade; b) Usando um assunto espelho em que o próprio ouvinte e sua circunstância fossem o personagem.

Eu percebera que no jeito de cantar em voga havia um claro acordo tácito entre o cantor e o ouvinte. $\mathrm{O}$ ouvinte 'protegia' e dava apoio à encenação do cantor 
... Minha tarefa era esboçar esse novo acordo tácito, substituindo a empatia gerada pela emoção [e rompendo] o elo forjado pela dramatização expressionista. ${ }^{6}$

Dentro desse contexto a estética experimental — entendida como uma intervenção que era feita com o intuito de provocar uma ampliação conceitual no campo artístico - podia ser encontrada com freqüência em letras de músicas, em peças teatrais e, especialmente, em diversos filmes, a maioria dos quais era enquadrada no chamado "Ciclo Marginal".

Ao lado desse surto criador e rebelde a censura - entendida não só como instrumento estatal, mas também como estratégias cerceadoras adotadas por subjetividades reacionárias — atuava reprimindo e limitando o espaço de criatividade de parcelas da juventude que atuavam no campo artístico. E isso não representava um aspecto específico para a história do Brasil, pois, como já se percebeu em relação a todo o Ocidente, em uma sociedade moderna, marcada pelo controle da produção e da circulação dos discursos, "não se tem o direito de dizer tudo ... não se pode falar de tudo em qualquer circunstância ... qualquer um, enfim, não pode falar de qualquer coisa"?

Mas o que ressalta, no universo em estudo, é o fato de que mesmo sabendo-se parte de uma sociedade intensamente vigiada, os jovens envolvidos com a arte experimental, além da transgressão comportamental, visavam à constituição de uma contra-linguagem, através da qual fosse possível expressar seu inconformismo em relação ao seu tempo. Essas vanguardas artísticas pretendiam, além de dizer coisas inovadoras, inovar no próprio ato diccional, escavando formas alternativas de se comunicarem. Desse modo, grande parte da energia crítica dessa geração de descontentes seria canalizada para atividades até então não utilizadas pelas formas tradicionais de luta política. ${ }^{8}$ Pode-se mesmo dizer que, sob a pressão da mundialização, esses jovens redescobriram a política forçando-a a escorregar do macro para o micro, ${ }^{9}$ encontrando em diferentes formas de expressão artística os instrumentos de sua dicção.

Os apontamentos que se seguirão são resultantes de um esforço que visa uma reflexão mais detida sobre a inventividade do cotidiano efetuada pelos cineastas ditos marginais do início da década de 1970. Trata-se, do ponto de vista deste trabalho, de sujeitos que, sob o impacto da pós-modernidade (Castelo Branco, 2005a), buscavam, através da linguagem filmográfica, ressignificar o mundo à sua volta e especialmente confirmar seu lugar na cidade. Os filmes em formato não-comercial que serão tratados aqui expressariam, à luz da teoria que se está utilizando, um movimento sub-reptício e astucioso, atra- 
vés do qual fragmentos da juventude brasileira compunham, diante das formas dominantes de pensamento no período, suas artes de fazer. ${ }^{10}$

\section{PRÁTICAS CAMINHANTES: FILMES EM SUPER-8 \\ COMO INSTRUMENTO DE APROPRIAÇÃO DA CIDADE}

Corpos femininos que se insinuam sob minúsculas saias e microblusas exibem, como se hasteassem uma bandeira (Imagem 1), ${ }^{11}$ a camisa de um sorveteiro com a marca daquele que, para elas, parece sintetizar o lugar praticado, para onde deveriam convergir os sujeitos de uma revolução comportamental. Pelas ruas, como que indiferentes às promissoras imagens da cidade em sua passagem para o moderno, serial killers multiplicam suas vítimas. Ao som dos primeiros acordes tropicalistas, os urubus passeiam a tarde inteira entre os girassóis, enquanto um jovem tresloucado, morto de amor, mata sua mãe a facadas, arrancando-lhe em seguida o coração, o qual oferece em presente à sua amada. De moto, ou flanando em um jipe aero-willys, um belo jovem de cabelos compridos guia os olhares na contramão. Como cada cidade contém todas as cidades, o Rio de Janeiro atrai como um ímã. Diáspora.

Essa poderia ser uma síntese muito radical dos filmes rodados em super8, entre 1972 e 1974, por jovens cineastas piauienses que se filiaram à influência das controvertidas personalidades de Torquato Neto e Davi Aguiar, ambos mortos tragicamente. ${ }^{12}$ Esses filmes, peças raras da memória audiovisual brasileira, constituem aquilo que, do ponto de vista deste trabalho, configura o 'espectro Torquato Neto' na filmografia marginal brasileira. A sua apropriação histórica é feita no sentido de problematizar essa produção, abrindo uma

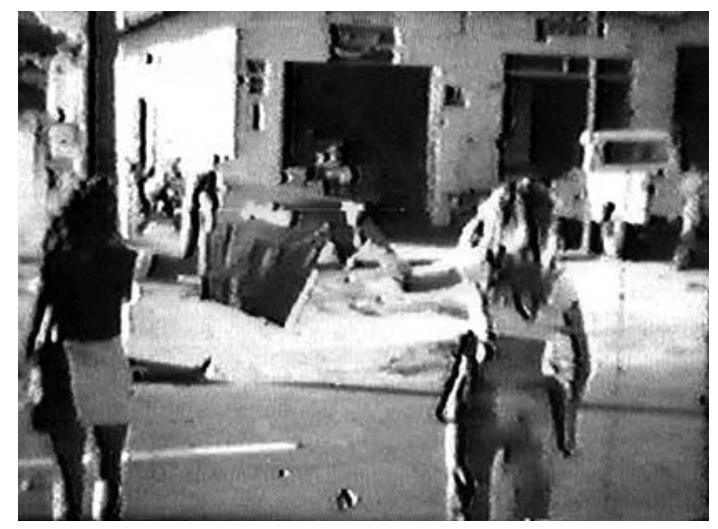

Imagem 1 - O Gelatti, em fotograma de Miss Dora, não é um espaço, enquanto lugar próprio, mas um lugar, enquanto espaço praticado. 
clareira que se espera promissora nos estudos históricos no Brasil. No estágio em que nos encontramos, com apenas parte da pesquisa concluída, já é possível, com uma rápida síntese dos filmes recuperados e digitalizados, demonstrar a força de seu valor histórico.

Um dos aspectos a destacar diz respeito ao fato de que por mais diversos que possam ter sido os lugares nos quais a atividade juvenil atuou rodando os filmes em estudo, a cidade acabou por figurar como o palco privilegiado no desenvolvimento dessa guerrilha semântica. Uma guerrilha que objetivava efetuar novas leituras com base na localização e ocupação dos lugares da cidade por meio de movimentos táticos. Numa atividade que ia além de um gesto meramente contemplativo, os jovens cineastas concentravam várias de suas manifestações principalmente no centro da cidade — fosse Teresina ou o Rio de Janeiro - , o que talvez decorresse do fato, já percebido, de que

o centro da cidade é instituído antes de tudo pelos seus jovens, pelos adolescentes. Quando estes exprimem a sua imagem da cidade, sempre têm tendência a restringir, a concentrar, a condensar o centro; o centro é vivido como lugar de troca das atividades sociais, das atividades eróticas no sentido amplo do termo. Melhor ainda, o centro da cidade é sempre vivido como espaço onde agem e se encontram forças subversivas, forças de ruptura, forças lúdicas. ${ }^{13}$

Dentro dessa lógica os cineastas experimentais em estudo estavam interessados, antes de tudo, em estabelecer uma nova semantização sobre a experiência da cidade, usando "o espaço físico da rua, reavaliando seu funcionamento e introduzindo novas atitudes" ${ }^{14}$ Essa atividade, a qual se dá quase sempre através das deambulações do homem ordinário na sua flanância investigativa pela cidade, é própria da vivência urbana, marcada pela necessidade de ler desenfreadamente a explosão de signos que a cidade propicia. Como já foi observado, "quem se desloca na cidade ... é uma espécie de leitor ... recolhe fragmentos de enunciados para anunciá-los em segredo. À nossa revelia somos todos esse leitor de vanguarda quando estamos numa cidade" (Barthes, 2001, p.228).

Davi vai guiar ${ }^{15}$ representa um clássico exemplo dessa flanância investigativa pela cidade. Trocadilho com o nome do principal protagonista Davi Aguiar —, o título remete às intenções centrais do filme: utilizar as noções de guia e contra-guia para, a partir de um deslocamento sobre a cidade de Teresina, ir dando visibilidade e afrontando os instrumentos panópticos de controle do espaço urbano, como os sinais de trânsito. A cida- 
de que emerge na tela, composta por um cenário bucólico que revela pacatos bate-papos de final de tarde nas calçadas, é repentinamente submetida a uma vertigem expressa por motocicletas e automóveis que deslizam por suas ruas em alta velocidade. Ao som ao mesmo tempo agressivo e melancólico da banda de rock Pink Floyd o protagonista sorri quase furiosamente, enquanto, cabelo ao vento e a pretexto de guiar sua motocicleta, arrasta os olhares na contramão. O argumento do filme se concentra em um esforço para ler os signos da cidade com base em uma afronta aos regulamentos. Urubus, por exemplo, são apropriados como instrumento de uma estética minoritária, problematizadora da própria noção de belo (Imagem 2). O destaque, entretanto, em Davi vai guiar, tanto quanto em O Terror da vermelha, ${ }^{16}$ é dado às tabuletas de trânsito, as quais são consumidas sempre no sentido da negação.

O gesto de subverter os regulamentos do trânsito, expressivos de um fragmento do discurso urbanista, configurariam uma escrita alternativa de Teresina. Como já se observou, o gesto de caminhar pela cidade - a que equivale deslocar-se na cidade - constitui uma atividade enunciativa, através da qual os caminhantes, delinqüentemente, subvertem a cidade idealizada pelas estratégias do discurso urbanista, revelando, em seu interior, "as práticas microbianas, singulares e plurais” (Certeau, 1994, p.175). A subversão caminhante, expressa em Davi Vai Guiar, não se faz apenas no sentido da negação, mas principalmente no da bricolagem. Essa bricolagem multiplica as possibilidades da cidade através de uma operação sub-reptícia de ultrapassagem de seus limites.

Mas é muito provável que Tristeresina (Imagem 3), a metáfora com a qual Torquato Neto recobriu sua cidade natal, ofereça o mais apropriado argumento para se pensar as cidades virtuais expressas nos filmes em estudo. Essa me-
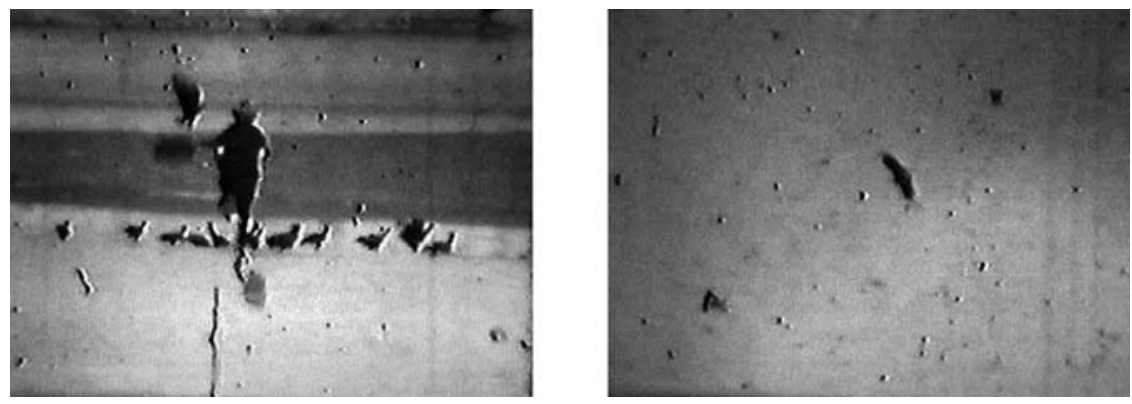

Imagem 2 - "E nos jardins os urubus passeiam a tarde inteira entre os girassóis", citação de "Tropicália" (Caetano Veloso, 1967) em fotogramas de Davi vai guiar. 


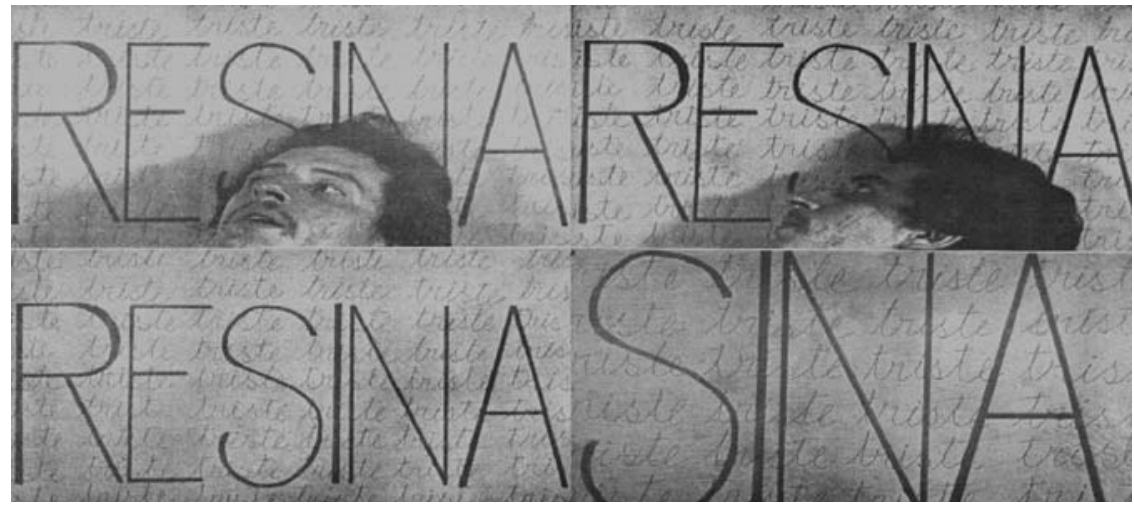

Imagem 3 - Tristeresina - uma das cartelas que abrem a trama em $O$ Terror da Vermelha.

táfora, que articula as noções de resina, tristeza e sina, constitui uma das cartelas de abertura de O Terror da Vermelha. Nela, o autor contrapõe seu corpo a um painel em duas dimensões, dividido em quatro partes, no qual é possível ler, em primeiro plano, as expressões 'resina' e 'sina', e, em segundo plano, manuscrito e repetido inúmeras vezes, a palavra 'triste'. A fricção das palavras opera diferentes resultados - triste resina, triste sina e tristeresina — todos utilizados taticamente como significados com os quais o poeta recobriria sua cidade natal. No filme, as perambulações de um assassino perseguindo suas vítimas pelas ruas de Teresina são utilizadas para uma investigação sobre o caráter formal do cinema (Imagem 4)

Rodado em 1972, a obra representa um dos lances finais da conturbada trajetória artística de Torquato Neto. Hoje uma das maiores cidades do país, ${ }^{17}$

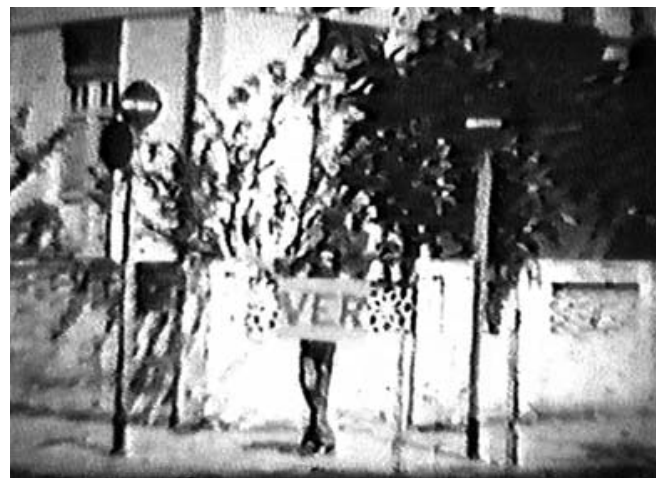

Imagem 4 - Fotograma de $O$ Terror da Vermelha: ênfase em uma visibilidade que remete aos sinais de trânsito como se sugerisse sua subversão. 
com perto de um milhão de habitantes, Teresina era, no início dos anos 70, uma típica cidade intermediária entre as cidadezinhas de interior e as metrópoles. Por um lado era a capital do estado, com todo o burburinho que essa condição impunha; por outro, era uma pacata cidade existindo preguiçosamente às margens dos rios Parnaíba e Poty. Mas para Torquato Teresina era, antes de tudo, uma cidade onde "não acontece nada, onde nunca passou um filme de Godard e onde cabeludo não entra na escola nem nas casas das famílias". ${ }^{18} \mathrm{O}$ filme, conforme se depreende do fragmento transcrito a seguir, seria feito no sentido de constituir um roteiro sentimental de Teresina:

Fui a Teresina pelo início de junho (sanatório meduna), entrei em contato com os rapazes que haviam feito o jornal gramma e partimos para um superoito de metragem média que resultou neste $O$ terror da Vermelha (ou qual outro nome escolherem). o material filmado percorria acidentalmente um fio de acontecimento, matéria de memória de uma só pessoa em equipe percorrendo roteiro de lugares, quintais, paisagens-plano geral. (Araújo Neto, 1982, p.339)

Realizado pouco antes da morte de Torquato, o filme revela que muitas daquelas temáticas que preenchiam as matérias de expressão torquateanas em seus poemas iniciais - uma atitude reativa em relação ao tempo, a idealização da infância e a repetida metáfora de Teresina como cidade-luz (Castelo Branco, 2005a) — se mantêm no roteiro. Ele, adulto, permanece "um homem desesperado andando à margem do rio Parnaíba”, enquanto Teresina, idealizada, permanece "uma cidade luz, musa advir" (Araújo Neto, 1982, p.335).

Essa exposição de seus lugares de memória Torquato utiliza como pretexto para apresentar a linguagem como algo instituinte da realidade, o que se pode exemplificar com a intrusão de elementos plásticos e poéticos avessos à ficção cinematográfica contemporânea, como cartelas com as expressões vir - ver - ou - vir - aqui (Imagem 5), as quais irrompem inesperadamente em diferentes quadros do filme. A irrupção, por sua vez, permite ver um percurso afetivo de Torquato Neto por Teresina e, mesmo, por sua existência, o que se revela na citação de outros filmes, como o Nosferato, de Ivan Cardoso.

Além do protagonista - Edmar Oliveira, hoje médico psicanalista com atuação no Rio de Janeiro - participaram como atores nessa única experiência de Torquato como diretor as atrizes Conceição Galvão, Claudete Dias e Herondina Mendes e os atores Durvalino Couto Filho, Paulo José Cunha, Carlos Galvão, Xico Ferreira e Arnaldo Albuquerque, além do próprio Torquato, que aparece rapidamente em uma cena em que é assassinado em frente ao Li- 

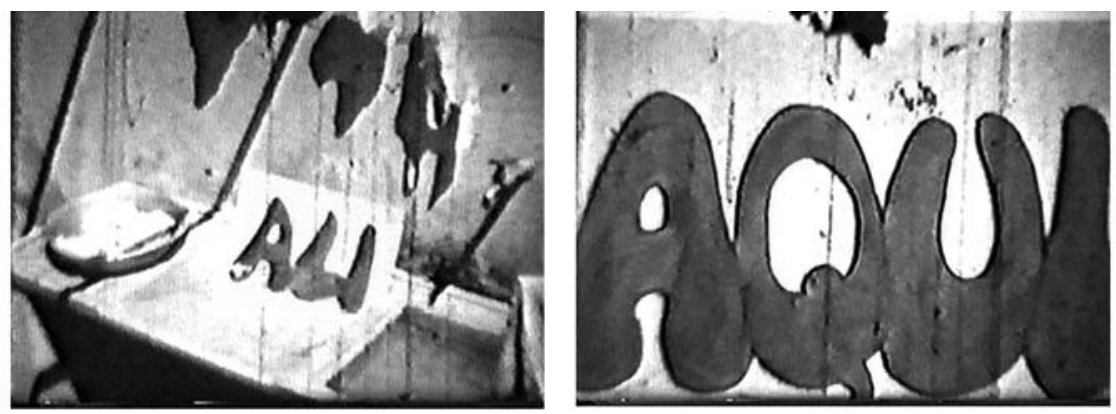

Imagem 5 - Elementos avessos à ficção cinematográfica irrompem em

O terror da vermelha para marcar e hierarquizar lugares, significando-os, e mesmo para problematizar as palavras como instrumentos comunicativos.

ceu Piauiense, uma das principais marcas identitárias de Teresina. Arnaldo Albuquerque e Carlos Galvão atuaram também como câmeras. O filme tem duração de 28 minutos, o que representa quase dez rolos de filme super-8.

Nessa atividade de filmar a cidade de Teresina, mapeando lugares de memória e desconstruindo o discurso utópico urbanista (Certeau, 1994), o filme Coração materno, de Haroldo Barradas, ${ }^{19}$ é aquele que revela mais nitidamente a grande influência dos tropicalistas sobre a primeira geração de cineastas experimentais no Piauí. Seu principal argumento é a apropriação da música homônima de Vicente Celestino (1894-1968), cuja releitura feita por Caetano Veloso, no disco panis et circensis, de 1968, a recolocou nas paradas de sucesso. Com o benefício da tragicidade expressa pela música — a qual narra o brutal assassinato de uma velhinha por um filho apaixonado que pretende dar o coração materno de presente à amada - o filme problematiza as relações entre pais e filhos e revisita as sociabilidades juvenis, procurando desconstruir a noção de amor romântico. No trajeto entre a amada que lhe pede o coração da mãe como prova de amor e a velhinha tipicamente católica que seria esfaqueada e esfolada, o protagonista cartografa Teresina, correndo loucamente por suas ruas, enquanto as tomadas constituem uma visão panorâmica da capital piauiense no início dos anos 70, permitindo revisitar sua arquitetura e reconhecê-la em suas sociabilidades pré-modernas. Com elenco bem menor do que aquele de Davi vai guiar, o filme tem duração de 14 minutos - o equivalente a pouco menos de cinco rolos de filme super-8 - e tem como protagonistas os jovens Pereira, Pierre Baiano, Edmar Oliveira e Arnaldo Albuquerque. Este último atua também como operador de câmera e editor das imagens. 
Mas de todos os filmes do espectro Torquato Neto Miss Dora ${ }^{20}$ é aquele que apresenta a dicção mais clara quanto ao esforço de síntese das marcas identitárias dessa geração. Provavelmente em razão dos sentimentos despertados por uma diáspora que levara, a partir de 1973, os jovens cineastas a deixar Teresina em busca de melhores condições de estudo e, mesmo, de mais espaço para sua arte, o filme possibilita pensar as táticas dessa geração na luta cotidiana pela instauração de seus espaços no interior da cidade (Imagem 6). Articulado em torno do bar Gelatti, principal ponto de encontro de parte da juventude teresinense no início dos anos 70, o filme toma Miss Dora, espécie de diva dos superoitistas, como centro de um enunciado que procura significar o espaço - enquanto lugar praticado - daqueles jovens e colocar em destaque o momento de emergência do corpo feminino erotizado no cenário público.

O bar Gelatti não expressaria, do ponto de vista da leitura que se está fazendo do filme, apenas o espaço de convergência de parcela da juventude teresinense, mas uma metáfora da cidade que aqueles jovens desejavam consumir num momento em que liberadores como a pílula anticoncepcional e a minissaia exigiam a fundação de novos lugares de sujeito. Além do próprio Edmar Oliveira, que concebeu e dirigiu o filme, atuaram, entre outros, José Alencar, Zé Henrique, Zé Raimundo, Naire Vilar, Nazaré Leite, Durvalino Couto e Xico Pereira. O filme tem duração de 13 minutos, o equivalente a pouco mais de quatro rolos de filme super-8.

No âmbito do conjunto de filmes que aqui está sendo tratado, dois deles testemunham a diáspora a que foram submetidos esses cineastas a partir de 1973. Trata-se de Porenquanto ${ }^{21}$ e Tupi-Niquim. ${ }^{22}$ Expressando as primeiras peripécias dos jovens cineastas piauienses após a diáspora que os espalhou por
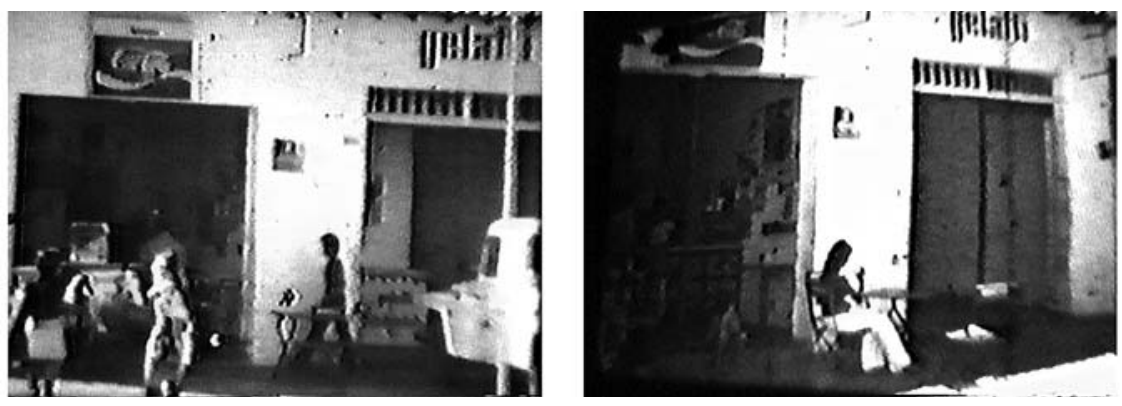

Imagem 6 - O bar Gelatti como exemplo de lugar praticado em fotograma de Miss Dora. 
diferentes cidades do Brasil, Porenquanto, rodado no Rio de Janeiro em 1973, permite ter uma visão ao mesmo tempo romântica e trágica dos morros da capital carioca. A trama retoma a temática do serial killer — presente, aliás, em quase todos os filmes dessa geração —, o qual, munido com uma foice, decepa cabeças ao mesmo tempo em que dá visibilidade à natureza — ainda preservada - que compõe o morro. Além de permitir pensar as matérias de expressão que compunham algumas subjetividades juvenis na época, o filme também é útil para indagar sobre as metáforas que, do ponto de vista de seus jovens realizadores, constituíam o humano. Porenquanto sinalizaria o intervalo entre Teresina e o Rio de Janeiro, o qual seria enfatizado em Tupi-Niquim.

Em Tupi-Niquim, rodado igualmente no Rio de Janeiro em 1974, a metáfora central é aquela que remete a um Brasil cindido entre o centro e a periferia — ou, se preferirmos, entre o litoral e o sertão —, o que está expresso logo no início com cenas mostrando a travessia de uma ponte que liga distintos lugares. A trama se desenvolve a partir do estranhamento de um sujeito recém-chegado ao Rio de Janeiro. Esse estranhamento, articulado em torno de um amor platônico e passional do protagonista por uma espécie de diva da cidade, oferece um bom instrumento para se pensar o multiculturalismo brasileiro e o processo de captura de subjetividades jovens por instrumentos como a mídia.

O filme expressa metaforicamente o encontro, promovido pelo cinema, das cidades subjetivas de seus realizadores. O diálogo entre Teresina e o Rio de Janeiro não é visível apenas no esforço para forçar a semelhança - o que se expressa na aparência dos fotogramas e na escolha dos enfoques —, mas principalmente na forma de mostrar os consumidores da capital carioca piauienses recém-chegados àquela cidade - como outsiders. O Rio de Janeiro mantém-se sempre inatingível, restando àquele que chega degluti-la através de uma operação que, pelo recurso à violência - expressa sempre através de um serial killer - , obrigue-a a ser outra coisa. Consolidadas marcas identitárias dos cariocas, como a Garota de Ipanema, o Aterro do Flamengo e a Baía da Guanabara, são seqüencialmente focadas como algo deslumbrante, fugidio e repulsivo. A remessa a uma matéria expressional nativa e minoritária - conforme expresso no título Tupi Niquim - é reforçada pela constante reafirmação das diferenças entre o outsider, vestido à moda hippie, e os insiders, sempre com paletós e gravatas. A absorção do estrangeiro na cidade dá-se através de sua cooptação pelas drogas. Num final tragicômico o Tupi Niquim é enforcado com os cordões da vestimenta do Frei Caneca, como se fosse tragado pela fascinante paisagem da Baía da Guanabara. 


\section{FOTOGRAMAS TÁTICOS: FILMAR COM O DEDO NO DISPARO}

Essa atividade filmográfica artesanal, a qual se exerce em diferentes lugares da cidade com o objetivo de apropriá-la, se dá através do uso de procedimentos táticos. $\mathrm{O}$ exercício tático, como se sabe, está necessariamente implicado na ocupação e subversão de um lugar próprio, controlado por regras estáveis. $\mathrm{O}$ ato de filmar, seja em Teresina seja no Rio de Janeiro e dentro das condições de existir que estão sendo tratadas, entrecortando ruas, vielas, avenidas, praças e demais lugares possuidores de uma organização própria, é uma intervenção que se faz no sentido de buscar um novo equilíbrio. Rompendo a sintaxe imposta pelo discurso urbanista e comportando-se segundo os moldes que lembram a conceituação certeauriana de caminhante delinqüente (Certeau, 1994), os cineastas em estudo, lutando ao mesmo tempo contra a precariedade técnica de seus equipamentos e a conjuntura política brasileira da época, empreenderam lances astuciosos de reorganização espacial a partir de uma elaboração própria dos seus quadros de referência. E esses movimentos táticos dariam a ver um momento de fundação de um novo discurso, de uma nova forma de nomear a realidade. As astúcias e estratégias das formas dominantes de pensamento, ávidas em capturar e enquadrar as diferentes subjetividades, reduzindo-as ao uniforme, não conseguiram impedir que os consumidores da cidade se articulassem a outros jogos de linguagem. A trajetória desses cineastas contraventores é uma marca da dinâmica da história contemporânea brasileira, em que várias foram as linguagens experimentais utilizadas por segmentos da juventude com vistas a obterem uma nova forma de se dizerem e de se inscreverem no debate político-cultural de sua época. O depoimento de Antônio Noronha, um dos cineastas em estudo, é ilustrativo dessa realidade:

Éramos um pessoal que se reunia e buscava outras formas de dizer as coisas. O nosso trabalho nessa época estava dentro de um contexto nacional que era, na época da ditadura, processar novas linguagens, movimentos e comportamentos que se confrontassem com o instituído... movimentos de libertação... coisa desse tipo. ${ }^{23}$

A prática do fazer cotidiano, do divagar pelos territórios da burla é sempre acompanhada pela noção de que o espaço em que se praticam tais ações é o lugar do outro, o que pressupõe a necessidade do movimentar-se constante para não ser capturado. Essa atividade produtiva que desemboca num novo e transgressor discurso, emana de uma equação formada pela experiên- 
cia individual somada à interação com outras práticas que a precedem. Dessa forma o cinema experimental em estudo pode ser compreendido como uma resultante dos 'diálogos' que, por sua vez, resultam da interação entre as experiências individuais e as experiências que estas catalisaram, pelos mais variados canais, das diversas manifestações culturais do período. Mais uma vez a fala de Antônio Noronha torna-se representativa para se pensar essa relação de absorção e ressignificação discursiva: "nós não tínhamos uma preocupação estética. Eu acho que era mais uma manifestação... um vômito daquilo que nós comíamos. Vômito que eu digo no bom sentido, ou seja, era a saída de uma informação que havíamos recebido".

Por trás de toda a inventividade desses cineastas, portanto, é possível perceber uma intenção política no agir com vistas à problematização do cotidiano surpreendente que os cortava. Na medida em que esses desenvolveram suas táticas enquanto consumidores da cidade, potencializaram um arsenal histórico através do qual é possível enxergar, na produção superoitista, o esforço não apenas de fundação de uma nova linguagem filmográfica, mas de problematização dos códigos culturais de uma época.

Os filmes aqui tratados, portanto, além de expandirem significativamente o conhecimento histórico que se tem da chamada 'marginália 70', poderão demonstrar que as manifestações artísticas dos anos 70 - especialmente o cinema marginal - ainda oferecem um vasto campo de intervenção para a pesquisa histórica. Ainda que tais filmes constituam um conjunto de fontes pouco usuais nos estudos históricos, esses filmes, quando lidos em termos de seu capital simbólico, permitem analisar as formas como os seus produtores se relacionavam com seu tempo, procurando inscrever sentidos sobre o mundo. Partindo da premissa de que os signos muitas vezes figuram sem a bela simplicidade das letras do alfabeto ou das tabuletas de trânsito (Barthes, 2001, p.178), este texto pretendeu fazer funcionar o conjunto cultural presente na estética underground das fontes em estudo, de forma a fazer tagarelar seus silêncios e provocar uma ampliação conceitual da história cultural brasileira.

Um dos aspectos a ressaltar é o fato de que a produção fílmica que está sendo tratada não encontrou espaço de veiculação nos circuitos exibidores da época, seja por problemas de mercado - rompimento com a lógica produção-distribuição-exibição - seja pela quebra da linearidade típica da narrativa fílmica - começo-meio-fim — ou, mesmo, por problemas com a censura, restando-lhes apenas os circuitos alternativos. ${ }^{24}$ Mas certamente a questão do mercado teve enorme peso. Não apenas no sentido de limitar a veiculação, mas especialmente na definição dos parâmetros de interlocução dos jovens cineastas. Sendo um gerador de energia e liberdade violentíssimo, ${ }^{25}$ a prá- 
tica de utilizar o super-8 para determinados segmentos da juventude estava atrelada ao desejo e à necessidade de transformar o objeto de consumo em instrumento de produção (Machado Jr., 2005, p.6). Isso demonstra que o uso do super- 8 transcendia o simples recurso a uma técnica emergente nas décadas de 1960 e 1970 e incidia sobre um esforço, por parte dos jovens cineastas em estudo, para utilizar esse objeto não apenas como um novo recurso técnico, mas como um instrumento de transgressão. Neste caso, a atividade de consumir um produto comercial — as bitolas de uso doméstico - era assumida como uma atitude de bricolagem, de inventividade, de criação e de produção. Isso porque os sujeitos, mesmo estando inseridos numa sociedade orientada pela lógica do mercado, não consomem de maneira passiva os produtos da indústria cultural. Esses homens ordinários assim o são justamente porque, através de uma bricolagem inventiva, conseguem se apoderar delinqüentemente dos códigos culturais e reinventar o cotidiano que pretendem usar. No limite, o ordinário se faz exatamente no esforço para reconduzir as práticas e as línguas à vida cotidiana (Certeau, 1994, p.64), trazendo a linguagem de seu uso filosófico de volta ao seu uso ordinário. ${ }^{26}$

Essa utilização do super-8 como uma espécie de instrumento de uma guerrilha semântica fez-se intensamente presente no universo de parcelas da juventude urbana nos anos 70. Com o benefício da fala do cineasta Durvalino Couto Filho - o qual atuou como ator, diretor e cameraman em vários dos filmes em estudo - é possível afirmar que os superoitistas também procuravam utilizar as bitolas domésticas como uma espécie de arma em favor de uma guerrilha artística: "O cinema super-8 era utilizado como o filme da família. Ele era um filme utilizado para filmar casamento, aniversário, batizado, mas a gente fez isso como uma proposta de guerrilha artística”. ${ }^{27}$

O que se está propondo é que a produção superoitista, vista em termos de sua época, representaria um esforço de parte de seus realizadores para abrir brechas e ocupar espaços alternativos não apenas no âmbito da produção artística, mas em seus próprios lugares de vivência. E mais do que isso: esses filmes representariam mesmo o interesse em interferir na realidade social fazendo coincidir arte e vida. A partir dessa produção marginal é possível entender a época em estudo como um período de redefinição de valores e de conceitos em vastos campos. Torquato Neto, que além de ser um dos cineastas em estudo foi um dos idealizadores do movimento tropicalista, ${ }^{28}$ ao assumir a editoria da coluna "Geléia Geral" no jornal carioca Última Hora, entre o final de 1971 e o início de 1972, transformou aquele espaço numa espécie de trincheira da arte experimental, especialmente do cinema marginal. Isso acabaria fazendo com que o poeta d'Os últimos dias de paupéria catalisasse, 
em torno de si, a fúria dos adversários do cinema marginal, especialmente a fúria de Glauber Rocha. De todo modo, coube a Torquato teorizar os parâmetros da produção fílmica marginal em sua relação com a realidade brasileira dos 'anos de chumbo', valendo-se do espaço que tinha em Última Hora. A importância de Torquato e de sua coluna pode ser medida em termos de avaliações como esta:

Não seria exagero afirmar que, hoje, a coluna "Geléia Geral” tornou-se material indispensável para o estudo e para se ter o feeling da polêmica história da cultura do início da década de 70 ... Lendo o conjunto de "Geléia Geral" temos a impressão de estar numa cabina de cinema vendo um superlonga-metragem de época. Correm na tela, a 24 quadros por segundo, Chacrinha, João Gilberto, o impacto de revolição (lição de voltar a querer) de José Celso com Gracias Señor, a fantástica descoberta do imagine de Lennon, da Chinoise, de Godard, o som que surgia com os novos baianos, os foxes e sambas de Luís Melodia, os ecos e os sinais dos grandes 'ausentes', como Hélio Oiticica, Glauber, Caetano, Gil, Macalé. E mais brigas, tiros, crises a quarenta graus. ${ }^{29}$

Um dos centros do programa tático de Torquato, no sentido certeauriano, consistia em conclamar seus leitores e simpatizantes a olhar a realidade com "o dedo no disparo" e atuar "dentro do campo de visão do inimigo, no espaço por ele controlado" (Certeau, 1994, p.100), ao mesmo tempo em que formulava táticas que permitissem, a si e a seus leitores, desviarem-se das redes de vigilância do Estado:

não se esqueça de que você está cercado, olhe em volta e dê um rolê. dá pra descobrir as brechas. eu ando por debaixo da avenida muito antes do metrô. ou será que eu não odeio tanto a ditadura da classe média que não queira transar com a moral dela? (Araújo Neto, 1982, p.348)

Relativamente àquilo que Torquato pensava especificamente em relação ao papel do cinema e especialmente em relação às utilidades do super-8 como instrumento de uma guerrilha semântica que refundasse sua época, o excerto transcrito a seguir configura uma bela síntese:

Quero liquidar com todas as teorias de montagem, tempo, gramática fílmica, etc. Isso tudo já se transformou numa linguagem. Eu quero liquidar essa linguagem e partir de volta a um approach bem primitivo, como uma criança. Sem conceituações. Buñuel falou que qualquer tipo de filme já é uma resposta a um prin- 
cípio onírico, uma espécie de sonho. De maneira que eu quero agora romper com os conceitos estruturais e começar de novo ... Acredito que a estrutura dos signos no cinema é mais importante do que a montagem. A montagem reprime as imagens e os signos ... Qualquer filme é a projeção de um sonho reprimido. E eu quero que esse sonho seja liberado, seja livre, sem nenhum limite. O cinema agora é feito por cineastas, 'filmakers', e eu quero que ele seja feito por todo mundo. Super oito... Oito crianças... Isso será o cinema liberto. (Araújo Neto, 1982, p.186)

O discurso torquateano configura-se como emblema do confronto que reúne ao mesmo tempo e sobre a mesma atmosfera fragmentos de uma gramática fílmica baseada nos cânones da sétima arte e uma nova enunciação que busca uma renovação de forma a solapar as certezas da teoria do cinema. Desse modo, os filmes em super- 8 produzidos na ambiência dos anos 70 podem ser entendidos como importantes instrumentos de intervenção na rede de significados instituídos e controlados pela sociedade, uma vez que estes empenharam-se no sentido de ampliar os limites desse ambiente fechado que é a época, implicando no cinema o novo acordo tácito já referido.

\section{CONSIDERAÇÕES FINAIS}

Numa primeira aproximação com a produção fílmica aqui apresentada, é possível constatar — até mesmo como forma de justificar o título - que esses filmes ganham significado exatamente no seu esforço de instituir uma contralinguagem, ou, retomando Wittgenstein (2005, p.48), pelo seu interesse em trazer a linguagem de seu uso filosófico de volta ao seu uso ordinário. Essa contra-linguagem, visível especialmente na maneira de subverter os códigos organizadores do espaço urbano, era esgrimida em favor de uma refundação das cidades. A partir das imagens que emanam dos filmes em estudo, foi possível constatar a presença de uma fragmentária rede de experiências empreendidas em diferentes espaços de Teresina e do Rio de Janeiro e articuladas a um forte entusiasmo pela realidade local. Mas ainda há muito a fazer.

Por um lado, já se concluiu que o cinema marginal — rótulo sob o qual se pode, apenas para efeitos didáticos, inscrever os filmes em estudo - é parte de um multifacetado universo artístico-cultural que representou a resposta de parcelas da juventude brasileira à emergência da condição histórica pósmoderna no país (Castelo Branco, 2005a). Mas há especificidades da linguagem filmográfica que demandam estudos complementares, os quais se somarão a este para responder 'o que' ou 'quem' eram aqueles garotos que, munidos 
de bitolas de cinema de uso doméstico, procuraram intervir em sua realidade com base em uma ampla interlocução com sua época.

Do mesmo modo, ainda resta friccionar essa produção fílmica com aquela que já mereceu vários estudos dentro e fora do âmbito acadêmico. Mas, principalmente, é ainda preciso, em benefício das histórias por trás desses filmes, mantê-los como acontecimentos, o que significaria mantê-los intempestivos, surpreendentes e perturbadores.

Se conseguirmos livrar esse acervo do perigo - praga para os historiadores - das imagens promissoras da evolução, preservando-os em sua dimensão acontecimental, estaremos evitando que ele seja reduzido, dentro da linha evolutiva da cultura brasileira, a um mero desdobramento de um marco qualquer.

\section{NOTAS}

${ }^{1}$ Pesquisa desenvolvida com auxílio financeiro do Conselho Nacional de Desenvolvimento Científico e Tecnológico $(\mathrm{CNPq})$, através da concessão de auxílio à pesquisa $(\mathrm{APq})$. Agradeço a distinta colaboração de Jaislan Honório Monteiro e Frederico Ozanan Amorim Lima, respectivamente bolsista de iniciação científica do CNPq e mestrando em História na UFPI. Ambos contribuíram dedicadamente na fase de levantamento de dados.

${ }^{2}$ PELBART, Peter P. A vertigem por um fio: políticas da subjetividade contemporânea. São Paulo: Iluminuras, 2000.

${ }^{3}$ Para uma leitura sobre a cidade como imagem do desejo, portanto como exterioridade, apesar de subjetiva, ver: GUATARI, Félix. Restauração da cidade subjetiva. In:

Caosmose - um novo paradigma estético. São Paulo: Ed. 34, 1992. p.167-79.

${ }^{4}$ CASTELO BRANCO, Edwar de A. Todos os dias de Paupéria: Torquato Neto e a invenção da Tropicália. São Paulo: Annablume, 2005a.

${ }^{5}$ Para uma leitura sobre as diferenças entre origem e começo em História ver: FOUCAULT, Michel. Nietzsche: a genealogia e a história. In: Microfísica do poder. (Trad. Roberto Machado). Rio de Janeiro: Graal, 1979.

${ }^{6}$ TOMZÉ. Tropicalista lenta luta. São Paulo: Publifolha, 2003. p.22.

${ }^{7}$ FOUCAULT, Michel. A ordem do discurso. São Paulo: Loyola, 1996. p.9.

${ }^{8}$ MESSEDER, Carlos Alberto P. O que é contracultura. São Paulo:Brasiliense,1987. p.30.

${ }^{9}$ CASTELO BRANCO, Edwar de A. Entre o corpo-militante-partidário e o corpo-transbunde-libertário: as vanguardas dos anos 60 como signos da pós-modernidade brasileira. História Unisinos, São Leopoldo (RS), v.9, n.3, p.218-29, São Leopoldo (RS), Universidade do Vale do Rio dos Sinos, set.-dez. 2005b.

${ }^{10}$ CERTEAU, Michel de. A invenção do cotidiano: 1 — artes de fazer. Petrópolis: Vozes, 1994. 
${ }^{11}$ As imagens que ilustram este texto foram obtidas de fotogramas de filmes domésticos rodados em bitolas de super-8. Em favor da memória audiovisual do período em estudo, supõs-se pertinente ignorar a sua baixa qualidade técnica.

${ }^{12}$ Torquato Neto, um dos idealizadores do movimento tropicalista, suicidou-se no Rio de Janeiro aos 28 anos, em 1972. Davi Aguiar, “o primeiro hippie de Teresina”, foi morto a facadas numa briga de rua em Fortaleza, no início dos anos 90.

${ }^{13}$ BARTHES, Roland. A aventura semiológica. São Paulo: Martins Fontes, 2001. p.278.

${ }^{14}$ MACHADO JÚNIOR, Rubens O cinema experimental no Brasil e o surto superoitista dos anos 70. In: AXT, Gunter; SCHÜLER, Fernando (Org.) 4x Brasil . Porto Alegre: Artes e Ofícios, 2005. p.7.

${ }^{15}$ DAVI VAI GUIAR. Durvalino Couto Filho, Teresina, 1972. 18,5 minutos. Cor/Som.

${ }^{16}$ O TERROR DA VERMELHA. Torquato Neto, Teresina, 1972. 28 minutos. Cor/Som.

${ }^{17}$ Teresina, de acordo com o último levantamento do IBGE, é a vigésima primeira maior cidade do Brasil.

${ }^{18}$ ARAÚJO NETO, Torquato P. Os últimos dias de paupéria. São Paulo: Max Limonad, 1982. p.339.

${ }^{19}$ CORAÇÃO MATERNO. Haroldo Barradas, Teresina, 1974. 14 minutos. Cor/Som.

${ }^{20}$ MISS DORA. Edmar Oliveira, Teresina, 1974. 13 minutos. Cor/Som.

${ }^{21}$ PORENQUANTO. Carlos Galvão, Rio de Janeiro, 1973. 26 minutos. Cor/Som.

${ }^{22}$ TUPI-NIQUIM. Xico Pereira, Rio de Janeiro, 1974. 17 minutos. Cor/Som.

${ }^{23}$ PESSOA FILHO, Antonio Noronha. Entrevista concedida a Jaislan Honório Monteiro em 21.01.2006.

${ }^{24}$ CASTELO BRANCO, Edwar de A.; MONTEIRO, Jaislan H. A quadratura do círculo, o enquadramento do ciclo: filmes em super-8 como repositórios de informações históricas. In: SIMPÓSIO NACIONAL DE HISTÓRIA CULTURAL, III — Mundos da imagem do texto ao visual. Anais... Florianópolis: GT História Cultural - Núcleo Santa Catarina Anpuh-SC; Clickdata Multimídia, 2006. p.1224-32.

${ }^{25}$ JOSÉ, Ângela. O cinema maldito. In: Antologia Prêmio Torquato Neto. Rio de Janeiro: Centro de Cultura Alternativa/RioArte, 1984. p.159.

${ }^{26}$ WITTGENSTEIN, Ludwig. Investigações filosóficas. Rio de Janeiro: Vozes, 2005. p.48.

${ }^{27}$ COUTO FILHO, Durvalino. Entrevista concedida a Jaislan Honório Monteiro em 6.02.2006.

${ }^{28}$ FAVARETTO, Celso. Tropicália, alegoria alegria. 3.ed. São Paulo: Ateliê editorial, 2000.

${ }^{29}$ HOLANDA, Heloisa B. de. Poetas rendem chefe de redação (II). Jornal do Brasil, Rio de Janeiro, Coluna B, 12 fev. 1983. p.12. 